А.В. Белоусова

Институт экономических исследований ДВО РАН, Хабаровск

\title{
А.Г. Исаев
}

Институт экономических исследований ДВО РАН, Хабаровск

\section{Инвестиции и экономический рост: случай Аальнего Востока}

Аннотация. В статье приводится характеристика инвестиционных процессов на Дальнем Востоке в их взаимосвязи с динамикой валового продукта макрорегиона. Оцениваются тенденции инвестиционной динамики с выделением отдельных периодов. Показана ограниченность во времени действия инвестиционных мультипликаторов в связи с концентрацией инвестиционных потоков в ресурсодобывающих секторах экономики региона и в секторе строительства крупных инфраструктурных объектов национального значения. Оценена инвестиционная функция для Дальнего Востока, на основе которой показано, что ускоренное развитие экономики Дальнего Востока (с превышением общенациональных темпов роста примерно на 1,5\% в год) до 2025 г. потребует такого увеличения объема и нормы инвестиций (при сохранении их структуры), которые не адекватны реальному инвестиционному потенциалу не только самого региона и государственных бюджетов, но и межрегиональной системы распределения ресурсов.

Ключевые слова: инвестиции, экономический рост, Дальний Восток, инфраструктура, инвестиционная функиия.

Классификация JEL: R11, E22, E60.

\section{Введение}

Тенденции экономического развития Дальнего Востока в XXI в., в том числе и результаты реализации крупнейшего инвестиционного проекта для проведения саммита Азиатско-Тихоокеанского экономического сотрудничества (АТЭС) (г. Владивосток), подтверждают невозможность существенного изменения ситуации в развитии региона, в том числе на основе привлечения внебюджетных инвестиционных ресурсов, без устранения исторически сформировавшихся барьеров (слабое развитие инфраструктуры; малая численность населения, низкая плотность и высокая миграция населения; завышенные тарифы на энергоносители; отсутствие налоговых преференций и т.д.). Между тем задача ускоренного и устойчивого экономического роста дальневосточных регионов объявлена приоритетной и ассоциируется с самостоятельным и әффективным развитием региона и генерацией им импульсов процветания и роста могущества России в целом ${ }^{1}$.
Согласно государственной программе РФ «Социально-экономическое развитие Дальнего Востока и Байкальского региона» (утверждена Постановлением Правительства РФ от 15.04.2014 № 308 (ред. от 30.03.2017)) ${ }^{2}$ одним из основных стимулов ускоренного роста экономики Дальнего Востока является увеличение кумулятивных объемов инвестиционных ресурсов. В программе приводятся прогнозные оценки соответствующих показателей, дифференцированные по некоторым получателям, но при этом отсутствуют данные о размерах экономических показателей федерального округа (к примеру, валового регионального продукта (ВРП)), обеспечиваемых соответствующими объемами инвестиций. Между тем только перспективная динамика дальневосточной экономики может свидетельствовать о присутствии ускорения (или инерции) в развитии региона. В настоящей статье рассматривается взаимосвязь между инвестициями в основной капитал и әкономическим

\footnotetext{
${ }^{1}$ См. материалы официального сайта: Президент РФ (http:/ / www.kremlin.ru/events/president/news/16990).

${ }^{2}$ Cм. http://www.consultant.ru/document/cons_doc_LAW_162190/.
} 
ростом на Дальнем Востоке, а также приводится оценка, полученная с помощью инвестиционной функции, перспективных масштабов капиталовложений, достаточных для обеспечения ускоренного роста региона.

\section{Являются ли инвестиции драйвером долгосрочного экономического роста на Дальнем Востоке}

Как правило, в работах, посвященных проблемам регионального роста и пространственной конвергенции, исследование движения капитала базируется на известных постулатах неоклассической теории: а) капитал совершенно мобилен в пространстве и одинаково доступен в любой его точке; б) географические различия в цене единицы капитального блага обусловлены только транспортными издержками; в) капитал размещается там, где имеется наиболее высокая норма доходности.

В действительности совершенная мобильность капитала и пространственное равенство цен капитальных благ - слишком сильные допущения, что обусловлено рядом факторов, среди которых следует выделить (Gertler, 1984): 1) соотношение предприятий различных размеров, локализованных на определенной территории; 2) смещение инвестиционных потоков от регионов с потенциально высокой нормой прибыли в сторону более традиционных полюсов роста; 3) промышленную инерцию, привязывающую инвестиции к уже созданным мощностям и замедляющую мобильность капитала. Не менее сильное допущение состоит в том, что критерием выбора направления миграции капитала является только норма доходности. При анализе пространственного распределения капитала необходимо учитывать существенное воздействие таких внеэкономических критериев, как геополитические, геоэкономические и социальные приоритеты. Это в полной мере проявляется в случае Дальнего Востока.
Характерной особенностью инвестирования, как частного, так и государственного, в экономику Дальнего Востока является перераспределение в пользу региона общенациональных инвестиционных ресурсов. Доля совокупных инвестиций в экономику Дальнего Востока в 2000-е годы устойчиво превышает долю вклада региона в формирование общенационального продукта: в 2005-2016 гг. доля созданной в регионе валовой добавленной стоимости составляла в среднем $4,7 \%$ общероссийской, доля государственных инвестиций $8 \%^{3}$ (частных - 7,6\%) (в 2016 г. объем инвестиций в основной капитал Дальневосточного федерального округа (ДФО) составил 903 млрд руб.). Динамика инвестиций в основной капитал в ДФО в 2005-2016 гг. была в целом положительной (рост на 25,4\%), однако явно можно выделить два разнонаправленных периода. Если до 2011 г. инвестиции росли высокими темпами (195\% за 2005-2011 гг.), то после 2011 г. наметился резкий спад инвестиционной активности (в 2016 г. 64\% к уровню 2011 г.). Основной причиной являлось завершение реализации крупных инфраструктурных проектов - строительства нефтепровода «Восточная Сибирь - Тихий океан», а также объектов, необходимых для проведения в 2012 г. в Приморском крае Саммита АТЭС 4 .

К концу первого десятилетия XXI в. Дальний Восток, который и в советский период имел сырьевую специализацию, значительно ее упрочил. Инвестиции в основной капитал направлялись главным образом в ресурсодобывающие сектора и строительство инфраструктуры. В 2011 г. инвестиции в сектор добычи полезных ископаемых составляли 20,5\% общего объема региональных капиталовложений, в сектор «Транспорт и связь»47,6\%. Однако к 2016 г. ситуация изменилась. Инвестиции в основной капитал в секторе «Транспорт и связь» в 2011-2016 гг. сократились на $65,8 \%$ и составили $25,3 \%$ общего объема капвложений в регионе, тогда как инве-

\footnotetext{
${ }^{3}$ В пиковом 2011 г. инвестиции федерального бюджета в основной капитал ДФО составляли $12,3 \%$ общероссийского уровня.

${ }^{4}$ О масштабах капиталовложений в эти объекты можно судить по доле Приморского края в объемах инвестиций в основной капитал ДФО: в 2011 г. она составляла 31\%, превысив уровень инвестиций в Сахалинскую область.
} 
стиции в ресурсодобывающий сектор увеличились на 23,3\%, а их доля выросла до $39,3 \%$. В остальных капиталоемких секторах промышленности - обрабатывающих производствах и производстве и распределении электроэнергии, газа и воды - сокращение инвестиций наблюдается после 2013 г. на 28,6\% (в 2012 г. на $59 \%)$.

Резкое сокращение инвестиций после 2011 г. сопровождалось стагнацией общей экономической динамики. Если за 2005-2011 гг. темп роста суммарного ВРП по ДФО составил 135,9\%, то за 2011-2015 гг. - менее $101 \%$. Стагнация в этот период объяснялась существенным падением ВДС в региональном строительном комплексе (на 47,6\%), что не удалось компенсировать даже ростом производства валовой добавленной стоимости в большинстве капиталоемких видов деятельности ${ }^{5}$ (добыча полезных ископаемых - 105,8\%; транспорт и связь - 104,4\%; обрабатывающие производства $-104,1 \%$ ).

Поэтому общий ответ на поставленный выше вопрос будет таким: региональная экономическая динамика в этот период в значительной степени определялась вариацией инвестиций в основной капитал. Вместе с тем это влияние проявлялось через следующие эффекты: рост инвестиций в ресурсодобывающий и инфраструктурный сектор - рост валовой добавленной стоимости в строительстве увеличение общего объема валовой добавленной стоимости региона в краткосрочном периоде (Минакир, 2017б, с. 53). Иными словами, основная часть инвестиций (через строительный комплекс) давала эффект в краткосрочном периоде - пока осуществлялось строительство инфраструктурных объектов и добывающих комплексов. Инвестиции же в сектора, характеризующиеся долгосрочным мультипликативным влиянием на экономический рост (обрабатывающая промышленность), незначительно влияли на общую динамику валовой добавленной стоимости. Отраслевая структура инвестиций является ограничением долгосрочного мультипликативного эффекта.
Рассмотрим, как влияет эта особенность на оценку количественной взаимосвязи между инвестициями и производством валового дохода для условий Дальнего Востока.

\section{Теория и эмпирическая оценка}

Будем использовать для анализа дальневосточной ситуации хорошо зарекомендовавшие себя в качестве адекватных моделей инвестиционного поведения на уровне национальной экономики модели акселератора, в которых желаемый для фирм, исходя из их рыночной стратегии, запас основного капитала $K^{*}$ в любой момент времени принимается пропорциональным объему выпускаемых благ $Y$ :

$$
K_{t}^{*}=\alpha Y_{t},
$$

где $\alpha-$ коэффициент пропорциональности (исходя из предпосылки о постоянстве во времени оптимального соотношения $K / Y$ ).

Достижение желаемого уровня запаса капитала в течение одного производственного периода является скорее исключением, чем правилом, возможно лишь приближение к нему с некоторой скоростью $\gamma$. Тогда объем инвестиций $I$ определяется (при отсутствии амортизации основных средств) как

$$
I_{t}=\sum_{i} \gamma_{i}\left(K_{t-i}^{*}-K_{t-i-1}\right)=\alpha \sum_{i} \gamma_{i}\left(\Delta Y_{t-i}\right),
$$

где $\Delta Y_{t-i}-$ изменение объема выпуска. Уравнение (2) интерпретируется как скорость сокращения влияния лаговых значений выпуска на текущий объем инвестиций, т.е. описывает ситуацию отставания фактического уровня инвестиций от желаемого уровня запаса капитальных благ с определенным лагом (об обратной трактовке модели см. ниже).

Д. Йоргенсон (Jorgenson,1967) предложил неоклассическую модель инвестиций, в которой фирма максимизирует текущую стоимость своего будущего потока доходов. Оптимальное инвестиционное поведение для прибылемаксимизирующей фирмы будет заключаться в такой корректировке запасов капитальных благ в каждом периоде, которая позволит при изменении стоимости ренты оставаться на оптимальной траектории услуг

\footnotetext{
${ }^{5}$ Сектор «Оптовая и розничная торговля», обладающий весомой долей в суммарном ВРП ДФО (11\% в 2015 г.), но низкой инвестиционной емкостью, демонстрировал также уверенный рост на интервале 2011-2015 гг. (+10,3\%).
} 
капитала. Д. Йоргенсон также показал, что модель гибкого акселератора является специальным случаем неоклассической модели (Ghali, Renaud, 1971).

Оценки ВРП, представленные в качестве функции от объемов инвестиционных ресурсов, по своей сути являются их мультипликатором. Ценность знаний о величинах мультипликативных әффектов заключается не только в получении представлений о масштабах влияния инвестиций на экономический рост, но и о длительности такого влияния (учитывая неизбежное присутствие временного лага между притоком инвестиций и получением желаемого результата в отраслевой или макроэкономических проекциях). Оценка инвестиционного мультипликатора предполагает использование модели с распределенным лагом (3):

$$
y_{t}=a+b_{0} x_{t}+b_{1} x_{t-1}+b_{2} x_{t-2}+\ldots,
$$

где $y-$ ВРП; $x$ - инвестиции в основной капитал; $t$ - точка временного отрезка, $a$ и $b$-оцениваемые коэффициенты модели.

Эта модель исходит из предположения, что влияние факторных переменных $(x)$ на результирующий признак $y$ не ограничено во времени (временной лаг не имеет заданных пределов, $t \rightarrow \infty)$. Коэффициент является оценкой величины краткосрочного мультипликатора, показывающего изменение среднего значения ВРП при единичном изменении объема инвестиций в текущий момент времени. Сумма коэффициентов $\sum_{i=0}^{\infty} b_{i}$ представляет собой долгосрочный мультипликатор, показывающий изменение ВРП при единичном изменении объема инвестиций в каждой точке исследуемого отрезка времени.

Количественная оценка краткосрочного и долгосрочного мультипликаторов получена при оценивании уравнения (3) при помощи преобразования Койка, т.е. в предположении, что влияние инвестиций на ВРП убывает по мере увеличения давности их привлечения в экономику, что отражает геометрическая прогрессия (4):

$$
b_{i}=b_{0} \lambda^{i}, \quad i=0, \ldots, \infty,
$$

где $0<\lambda<1$ трактуется как скорость сокращения масштаба влияния инвестиций на ВРП по мере увеличения временного лага от момента притока соответствующих инвестиций в экономику. Подставляя значения $b_{i}$ в (3), получаем уравнение (5):

$$
y_{t}=a+b_{0} x_{t}+b_{0} \lambda x_{t-1}+b_{0} \lambda^{2} x_{t-2}+\ldots,
$$

вычитая из которого почленно аналогичное уравнение, построенное для предыдущего момента времени и умноженное на параметр $\lambda$, переходим к модели авторегрессии:

$$
y_{t}=a(1-\lambda)+b_{0} x_{t}+\lambda y_{t-1} .
$$

Коэффициенты уравнения (6) оценены на основе обобщенного метода наименьших квадратов (Зарецкая, Осиневич, 2010) $\left(b_{0}=0,46, a=1770522, \lambda=0,76\right), \quad$ что п позволило посредством обратного хода проведенных преобразований вычислить коэффициенты модели (3).

Применение преобразования Койка к модели (3) с использованием сопоставимых данных по ДФО за 2000-2015 гг. (ВРП, млн руб.; инвестиции в основной капитал, млн руб., база - 2015 г.) позволило получить следующую зависимость:

$$
\begin{aligned}
& y_{t}=1770522+0,46 x_{t}+0,35 x_{t-1}+0,26 x_{t-2}+ \\
& +0,20 x_{t-3}+0,15 x_{t-4}+0,12 x_{t-6}+0,09 x_{t-7}+0,07 x_{t-8}+ \\
& +0,05 x_{t-9}+0,04 x_{t-10}+0,03 x_{t-11}+0,02 x_{t-12}+0,01 x_{t-13} .
\end{aligned}
$$

Величина долгосрочного мультипликатора определяется как

$$
\sum_{0}^{\infty} b_{i}=b_{0}+b_{0} \lambda+b_{0} \lambda^{2}+\ldots=\frac{b_{0}}{1-\lambda} .
$$

Краткосрочный мультипликатор, равный 0,46 , показывает, что каждый рубль инвестиционных ресурсов, вложенный в текущий год, обеспечивает прирост ВРП макрорегиона на 46 коп. в этом же году. Долгосрочный мультипликатор, равный 1,91, показывает, что каждый рубль инвестиционных ресурсов, вложенных в текущем году, в конечном счете обеспечит рост ВРП региона на 1,91 руб. С точки зрения темпов роста увеличение в текущем году инвестиций на $1 \%$ обеспечит прирост ВРП на $0,09 \%$ в этом же году и на $0,35 \%$ - в долгосрочной перспективе.

Знание величин долгосрочного и краткосрочных мультипликаторов дает возможность получить оценки параметров $k_{i}$, характеризующих масштабы влияния инвестиций на динамику ВРП: 


$$
k_{i}=b_{i} / \sum b_{i} .
$$

Согласно формуле (9) для Дальневосточного региона в год притока инвестиционных ресурсов реализуется 18,2\% их долгосрочного влияния на динамику ВРП. В последующий год $-13,8 \%$; через 3 года $-10,5 \%$ и т.д., через 11 лет - лишь 1,2\% (см. рисунок). Таким образом, более $50 \%$ влияния реализуется в течение первых пяти лет после вложения инвестиционных средств.

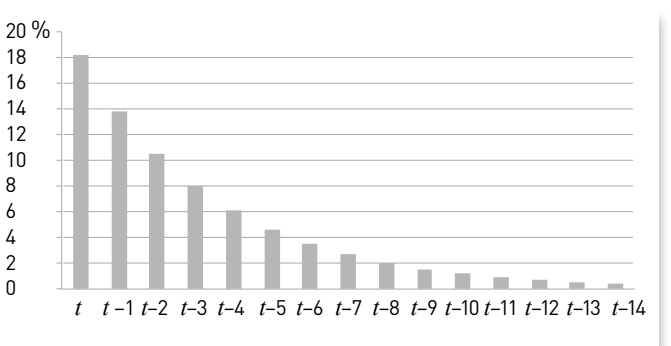

Рисунок

Действие долгосрочного инвестичионного мультипликатора ДФО

Из рисунка видно, что эффект от инвестиций в момент времени t постепенно затухает в течение последующих лет. Это означает, что сокращение инвестиций сначала оборачивается стагнацией экономического роста (как это имеет место после 2011 г.), а уже в ближайшей перспективе неизбежно грозит уменьшением производства региональной валовой добавленной стоимости. Пролонгация инвестиционной динамики 2013-2016 гг, а именно сохранение среднегодового темпа роста инвестиций на уровне 96\%, приведет к тому, что к 2025 г. значение ВРП составит 79,4\% по отношению к 2013 г. вместо предполагаемых в программах развития $180 \%$.

Инвестиционные мультипликаторы позволяют оценить объем инвестиционных ресурсов, необходимый для выполнения намерений государственной программы «Социально-экономическое развитие Дальнего Востока и Байкальского региона до 2025 года». Согласно этой программе для формирования условий ускоренного развития Дальнего
Востока требуется обеспечить превышение среднегодового темпа прироста совокупного ВРП Дальнего Востока на 1,5\%, - иными словами, исходя из «Прогноза-2030», среднегодовой темп роста в регионе должен составлять 105-107\%.

Расчеты показывают, что для обеспечения ускоренного развития Дальнего Востока такими темпами потребуется поддержание нормы инвестиций на уровне не менее $40 \%$ к 2020 г. и порядка $48 \%$ - к 2025 г. За период 2005-2015 гг. на Дальнем Востоке близкая норма накоплений наблюдалась только в 2011 г. (41,9\%), на который пришелся пик капитальных вложений в строительство инфраструктуры. Затем норма накопления неуклонно снижалась и в 2014-2015 гг. составляла только 25\%. Такая норма характерна для многих развитых стран, но она предполагает очень высокую эффективность использования капитала, совершенно другую структуру экономики и недостаточна для ускоренного роста развивающейся экономики ${ }^{6}$. Перспективы не только изменения структуры региональной экономики, но и повышения әффективности использования основного капитала туманны. Правда, в 2005-2013 гг. инвестиции в активную часть фондов на Дальнем Востоке увеличились на $65 \%$, но в 2014-2015 гг. их объем сократился на $18 \%$, а доля в общем объеме не превышает 40\%. Учитывая, что их значительная часть идет на возмещение выбывающего оборудования, перспективы коренного технологического обновления и повышения эффективности использования ресурсов выглядят весьма отдаленными.

\section{Заключение}

После 2011 г. поступление инвестиций на Дальний Восток резко сократилось, а темпы әкономического роста в целом, несмотря на положительную динамику в ряде капиталоинтенсивных секторов, существенно замедлились. Такая картина слабо увязывается с задачами ускоренного роста региона

\footnotetext{
6 По оценкам Л.В. Мельниковой (Мельникова, 2010), в период 2001-2007 гг. в Дальневосточном федеральном округе в среднем за указанный период норма накопления была наивысшей среди всех федеральных округов (30,6\%).
} 
в средне- и долгосрочной перспективе. Оцененный авторами долгосрочный инвестиционный мультипликатор явно указывает на то, что при данной структуре экономики региона, а также уровне развития коммунальной и бизнес-среды (Минакир, 2017а) для его ускоренного роста требуется инвестиционная накачка, причем при постоянно возрастающих масштабах, не свойственных даже для периода ускоренной индустриализации 1930-х годов. Соответственно, это вновь потребует усиления перераспределения национальных ресурсов в пользу Дальнего Востока. Сокращение же нормы инвестирования (или хотя бы ее поддержание на уровне последних лет) неизбежно приведет не только к стагнации экономического роста, но и к снижению производимой регионом совокупной добавленной стоимости уже в среднесрочной перспективе.

Разумеется, эти рассуждения справедливы при условии сохранения сложившейся структуры инвестирования, которая объективно обусловлена сформировавшейся экономической специализацией Дальнего Востока. Для повышения долгосрочной отдачи от инвестиций (или, что то же самое, увеличения долгосрочного инвестиционного мультипликатора) требуется не только количественное, но и качественное изменение структуры капиталовложений: не просто повышение доли инвестиций в обрабатывающую промышленность ради увеличения общей массы новых производств, но в создание связей для запуска механизмов внутрирегиональной генерации доходов; не просто вложения в инфраструктуру, но в инфраструктуру, повышающую качество жизни. Но и этот процесс сопряжен с масштабным перераспределением национальных ресурсов в пользу региона.

До сих пор модель ускоренного роста Дальнего Востока заключалась в накачивании региона бюджетными ресурсами, что, очевидно, невозможно на протяжении длительного периода, особенно после кризисов 2009 и 2014 г., ухудшивших макроэкономическую ситуацию и существенно сокративших доходную часть бюджета. Кроме того, для масштабных государственных инвестиций необходимо наличие крупных, системообразующих проектов. Подобные проекты в настоящее время реализуются в других регионах страны и требуют соответствующего перераспределения финансовых ресурсов не в пользу Дальнего Востока.

Оценки, полученные в настоящей работе для нормы капиталовложений, необходимой для ускоренного роста әкономики Дальнего Востока, конечно, подразумевают сложившуюся отраслевую структуру инвестиций, а следовательно, высокий удельный вес государственного участия. Однако очевидно, что для повышения эффективности экономики региона необходима ее структурная перестройка. Но здесь ограничением выступает специализация региона и сложившаяся структура спроса (прежде всего внерегионального). Изменений в этом направлении невозможно достичь простым размещением новых производств. Здесь вступает в силу множество факторов, большая часть которых слабоуправляемы или неуправляемы вообще (например, место Дальнего Востока в сложившейся системе разделения труда и торговых потоков в АзиатскоТихоокеанском регионе).

Без выполнения всех этих условий задача ускоренного развития Дальнего Востока будет сводиться к перманентному наращиванию объемов общенациональных ресурсов в регионе. Запуск механизмов эндогенных источников развития (что равносильно повышению долгосрочных эффектов региональных инвестиций) заключается в такой структурной перестройке экономики, которая позволит региону стать частью институциональных форматов кооперации в Северо-Восточной Азии, обретя, таким образом, конкурентные преимущества в рамках национальной экономики.

\section{ЛИТЕРАТУРА}

Зарецкая В.Г., Осиневич Л.М. (2010). Оценка влияния инвестиций на размер валового регионального продукта (на примере Курской области) // Региональная экономика: теория и практика. № 46 (181). C. 14-18. 
Мельникова Л.В. (2010). Оценка географических направлений инвестиционных потоков / / Регион: экономика и соииология. № 3. C. 81-101.

Минакир П.А. (2017а). Ожидания и реалии политики «поворота на Восток» // Экономика региона. Т.13. Вып.4. С. 1016-1029.

Минакир П.А. (ред.) (2017б). Российский Дальний Восток на пути в будущее. Институт экономических исследований ДВО РАН. Хабаровск: ИЭИ ДВО РАН.

Gertler М. (1984). Regional Capital Theory // Progress in Human Geography. Vol. 8 (1). P. 50-80.

Ghali M., Renaud B. (1971). Regional Investment and Regional Growth: Some Empirical Evidence / / Southern Economic Journal. Vol. 38 (2). P. 219-229.

Jorgenson D. (1967). The Theory of Investment Behavior. In: "Determinants of Investment Behavior". Ferber R. (ed.). New York: NBER.

Поступила в редакиию 2 февраля 2018 г.

\section{REFERENCES}

(with English translation or transliteration)

Gertler M. (1984). Regional Capital Theory. Progress in Human Geography, 8 (1), 50-80.

Ghali M., Renaud B. (1971). Regional Investment and Regional Growth: Some Empirical Evidence. Southern Economic Journal, 38 (2), 219-229.

Jorgenson D. (1967). The Theory of Investment Behavior. In: "Determinants of Investment Behavior". Ferber R. (ed.).New York: NBER.

Melnikova L. (2010). Assessing the Geography of Investment Flows. Region: Economy and Sociology, 3, 81-101 (in Russian).

Minakir P. (2017a). "Turn to the East Policy": Expectations and Reality. Economy of Region, 13 (4), 1016-1029 (in Russian).

Minakir P. (ed.) (2017b). The Russian Far East: on the Way to Future. Economic Research Institute, Far Eastern Branch of the Russian Academy of Sciences. Khabarovsk: ERI FEB RAS.

Zaretskaya V., Osinevich L. (2010). Estimation of Investment Impact on Kursk Oblast' GDP. Regional Economy: Theory and Practice, 46 (181), 14-18 (in Russian).

Received 2.02.2018

\title{
A.V. Belousova \\ Economic Research Institute Far Eastern Branch Russian Academy of Sciences, Khabarovsk, Russia
}

A.G. Isaev

Economic Research Institute Far Eastern Branch Russian Academy of Sciences, Khabarovsk, Russia

\section{Investment and Economic Growth: the Case of the Russian Far East}

\begin{abstract}
The article describes the characteristics of investment processes in the Far East and their relationship with the dynamics of the macro-region's gross product. Trends in investment dynamics are assessed with the identification of individual periods. The time-limited effect of investment multipliers is shown in connection with the concentration of investment flows in the resource-producing sectors of the regional economy and in the sector of large national infrastructure facilities' construction. The investment function for the Far East is estimated on the basis of which it is shown that the accelerated development of the economy of the Far East (exceeding the national growth rate by about $1,5 \%$ per year) until 2025 will require an increase in the volume and rate of investment (while maintaining their structure). These amounts are not adequate to the real investment potential not only of the region and state budgets, but also of the interregional resource allocation system.
\end{abstract}

Keywords: investment, economic growth, Russian Far East, infrastructure, investment function.

JEL Classification: R11, E22, E60. 